\title{
A Flexible Nozzle for a Small Supersonic Wind Tunnel*
}

\author{
SATISH DHAWAN $\dagger$ AND ANATOL ROSHKO† \\ California Institute of Technology
}

\begin{abstract}
SUMMARY
The design of a small supersonic wind-tunnel test section ( 4 by 10 in.) incorporating a flexible nozzle is outlined. The flexible nozzle consists of a high-strength stepped steel plate. Two screw jacks provide an easy means of continuously changing the nozzle's shape according to the aerodynamic requirements. The boundary-layer compensation can also be varied during operation. Pressure surveys, together with schlieren and interferometric analysis of the test section, show the flow to be uniform over the operating range ( $M=1.1$ to 1.5$)$.
\end{abstract}

\section{INTRODUCTION}

$\mathrm{T}$ HE DEVELOPMENT OF experimental research in transonic and supersonic flow has increasingly demanded the use of a wind tunnel with continuous control over the flow parameters. Since the air speed in a supersonic wind tunnel is determined completely by the geometry of the nozzle, it is necessary to provide a different nozzle shape for each different required speed. The use of a flexible nozzle permits a continuous change in the flow Mach Number and constitutes a considerable advantage and improvement over the alternative of using a series of fixed geometry nozzles. The idea of using a flexible nozzle is not new, and there are in existence and operation in this country several supersonic wind tunnels incorporating the device. However, as far as can be determined from published descriptions of these wind tunnels, the flexible nozzle with its shape-changing mechanism is rendered complex by the range and accuracy requirements. For instance, in order to change the nozzle shape the wind tunnel has to be shut down and the required changes made in small degrees of adjustment. During the past year or so there has been in use a flexible nozzle of exceptionally simple design in the 4 - by 10 -in. Transonic Tunnel at the California Institute of Technology. The supersonic range of the tunnel is limited from

Received March 22, 1950.

* The authors wish to acknowledge the supervision and help of Dr. Hans Wolfgang Liepmann, under whose direction the design was executed. Harry Ashkenas rendered valuable assistance in the mechanical design.

$\dagger$ Guggenheim Aeronautical Laboratory.

$\ddagger$ The test section described here is a modification on the original test section of the 2 - by 20 -in. high subsonic tunnel built in 1944 under A.A.F. contract for high-speed flow investigations. A study of boundary-layer and shock-wave phenomena is at present in progress under N.A.C.A. sponsorship; the design presented here was executed in the course of this work. Results of recent research in the tunnel are being published elsewhere by the N.A.C.A. approximately $M=1.1$ to 1.5 , and this fact is fully exploited in the interests of simplicity to achieve a design that permits continuous shape changes in the nozzle during operation while retaining accuracy and uniformity of flow. Over the major portion of the operating range, the only operation required to change the flow Mach Number is the turning of a single jackscrew. This paper briefly outlines the interesting features of this tunnel with special attention to the design, construction, and use of the flexible nozzle.

\section{Description of Test Section}

The working section of the GALCIT 4- by 10- by 48-in. transonic tunnel is sketched in Fig. 1 showing the essential features of the design. The floor block of the test section carries the one-wall flexible nozzle plate, together with the swiveling jackscrew controls. The floor is hinged just downstream of the main jack, and its downstream end can be raised or lowered by means of a screw jack. This allows alterations in boundarylayer compensation during operation. The ceiling block of the tunnel supports the traversing mechanism and contains a narrow slot for operation of the traversing arm. A pressure box, with access panels mounted on the ceiling block, encloses the traversing mechanism and seals it to the test section. Pressure-sealing of the test section is secured by means of rubber tube-ingroove seals between the sidewalls and floor and the ceiling blocks. The sidewalls are made in panels and allow the window to be located anywhere in the 48-in. length of the test section. The main flexible nozzle consists of a continuous spring steel plate $45^{1 /} / 4$ in. long of varying thickness, of which 36 in. forms the flexible nozzle and the remainder is the floor of the test section (see Fig. 1). It is anchored in the contraction with the downstream end also direction-fixed, but it is free to move horizontally on rollers when deflected by the jacks. A second flexible nozzle plate begins where the primary nozzle ends. The flexible second throat acts as a speed control during subsonic operation of the tunnel and may be used as an adjustable supersonic diffuser during supersonic runs.

\section{Design Considerations}

\section{(1) Aerodynamic Nozzle Shapes}

The supersonic range of Mach Numbers in the tunnel is from $M=1.1$ to 1.5 . Fig. 2 shows the theoretical 


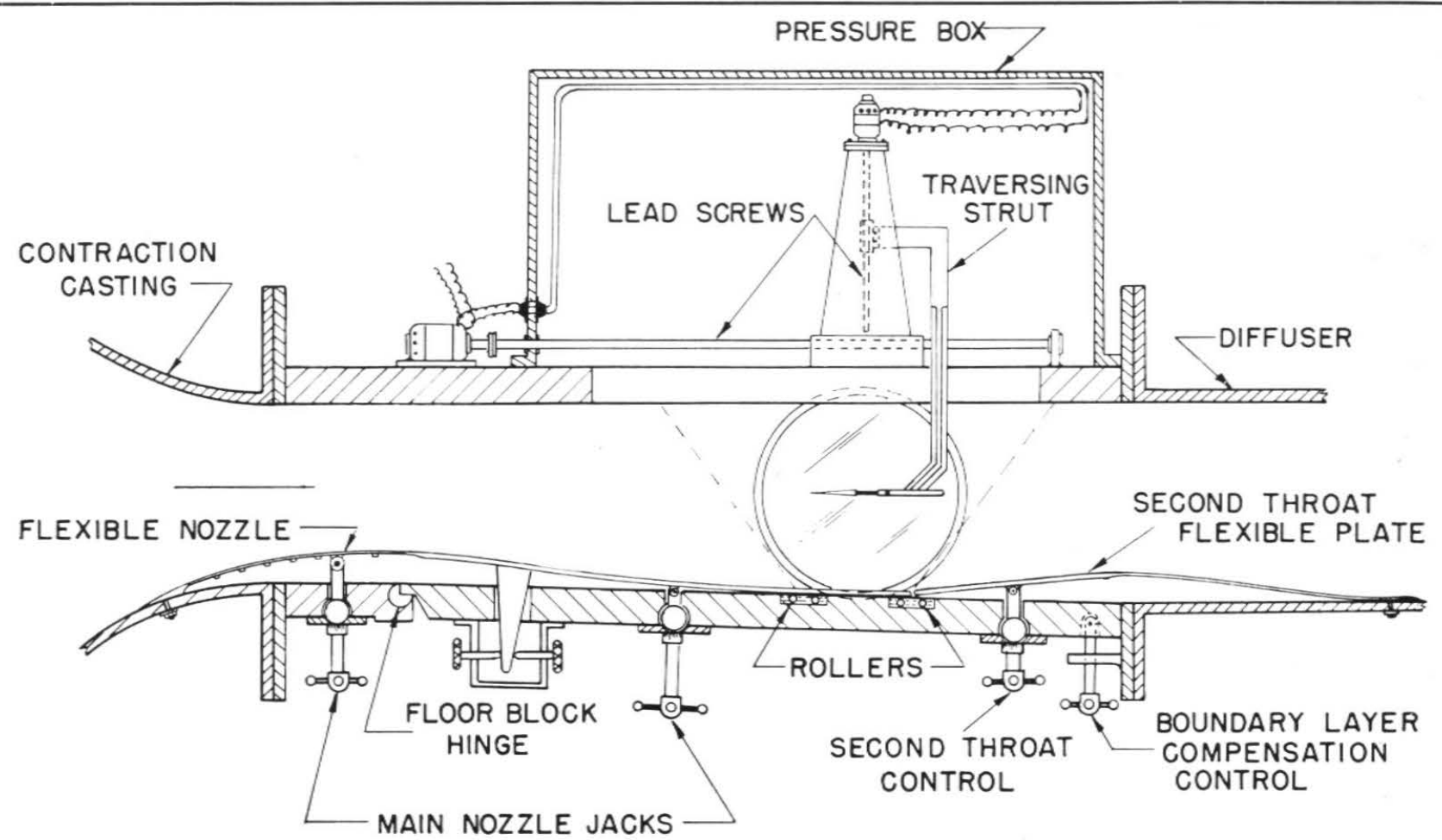

Fig. 1. Sketch of the GALCIT 4- by 10 - by 48 -in. transonic-tunnel test section.

nozzle shapes covering this range. These shapes were obtained graphically by the well-known method of twodimensional characteristics. ${ }^{1}$ The fundamental procedure in this method consists of assuming an initial expansion curve starting from zero inclination at the throat up to the nozzle expansion angle $\theta$ (Fig. 3), which must be less than, or at most equal to, half the Prandtl-Meyer angle associated with the final Mach

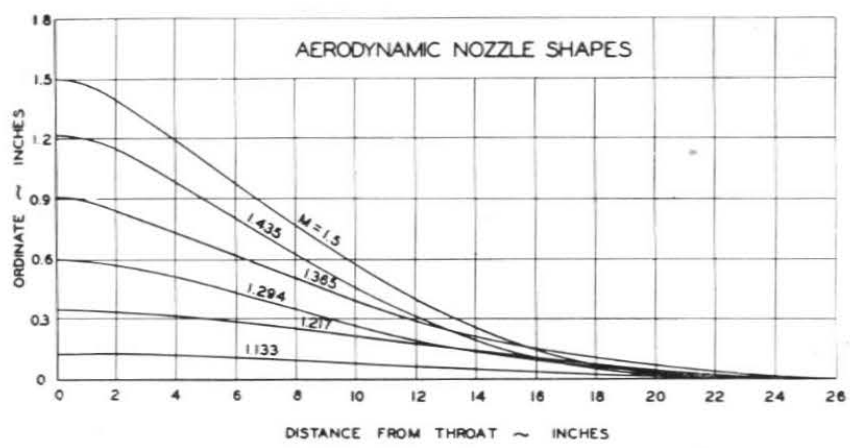

FIG. 2.

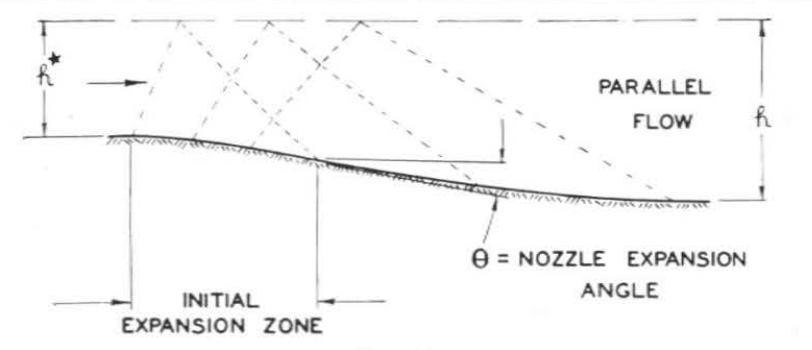

FIG. 3.
Number. The initial expansion curve is then divided into suitable straight segments. The expansion wavelets generated by this convex initial curve determine uniquely the subsequent form of the nozzle for parallel flow at the exit. For a required Mach Number in the test section, there is thus an infinity of possible initial curve and expansion angle $\theta$ combinations. Theoretically, the shortest length nozzle would be obtained by using the maximum value of $\theta$ (equal to half the Prandt1-Meyer angle) and an initial expansion of infinite curvature -i.e., a sharp corner at the throat. Actually, however, the presence of boundary layer limits the rate of expansion. For design purposes, a radius of curvature at the throat of approximately two to four times the test-section height may be used. In choosing the aerodynamic shapes shown in Fig. 2, the initial expansion wave and the nozzle slope $\theta$ were so adjusted as to give constant length nozzles (throat to exit) for the various design Mach Numbers. This permitted the use of a constant length flexible plate for the supersonic nozzle and simplified the mechanical design considerably.

\section{(2) Boundary-Layer Compensation}

The theoretically obtained nozzle shapes do not take into account the growth of the boundary layer on the walls of the tunnel. In order to allow for this, it is usual to displace the physical walls at each point by the "displacement thickness" of the boundary layer at that point. One method of obtaining approximate estimates of the boundary-layer growth is to assume the pressure gradient on the walls as obtained by the in- 
viscid flow computation and, then, to use boundarylayer theory to calculate the displacement thickness. In the design under discussion, the compensation for boundary layer was taken into account in a more elementary fashion. Experience in the previous test section of the wind tunnel had shown that a linear correction of $0.021 \mathrm{in}$. per in. in the walls was sufficient to allow for the boundary-layer growth. In addition, the present design includes provision for alterations in the allowance with the tunnel in operation. Subsequent results justified the estimates used.

\section{The Nozzle Plate}

\section{(1) Requirements}

(a) The nozzle plate should be able to reproduce, during operation, any aerodynamic nozzle shape in the required range.

(b) The shape-changing mechanism should be simple and nozzle settings accurately repeatable.

(c) The plate must be free from local distortion and vibrationally stable during operation of the wind tunnel.

\section{(2) Plate Shape and Control Configuration}

Study of the aerodynamic shapes (Fig. 2) to be reproduced by the nozzle plate shows that, in general, the aerodynamic shapes have an initial region of relatively high curvature followed by an almost straight portion containing an inflexion point (reversal in sign of the curvature). The terminal section of the shapes is seen to have relatively the largest length and a uniformly decreasing curvature. Fig. 4 shows the curvatures of various configurations of a plate represented as an elastic beam in relation to the curvatures of a representative aerodynamic shape. It is clear that a minimum of two controls is required to produce the required change in sign of curvature in the plate. Fig. 4 also shows how the jacks for changing the shape of the nozzle should be located. Since the greatest curvature in the plate is produced in the vicinity of the main jack, this must be situated close to the throat of the nozzle. It is also evident that it is impossible exactly to reproduce the required curvatures with a continuous plate of constant thickness. Fig. 4d shows the manner in which a variation in moment of inertia of the plate cross section may be used to advantage in bringing the elastic and aerodynamic shape curvatures closer together. The second integrals of these curves-i.e., the actual shapes - would then be still closer. In order to secure smooth entrance and exit conditions at all Mach Numbers, it is highly desirable to have the ends of the nozzle plate fixed in direction. A comparative study of several configurations along the lines indicated above led to the adoption of the configuration schematically represented in Fig. 5. The nozzle plate consists of a stepped beam loaded at two points by screw jacks

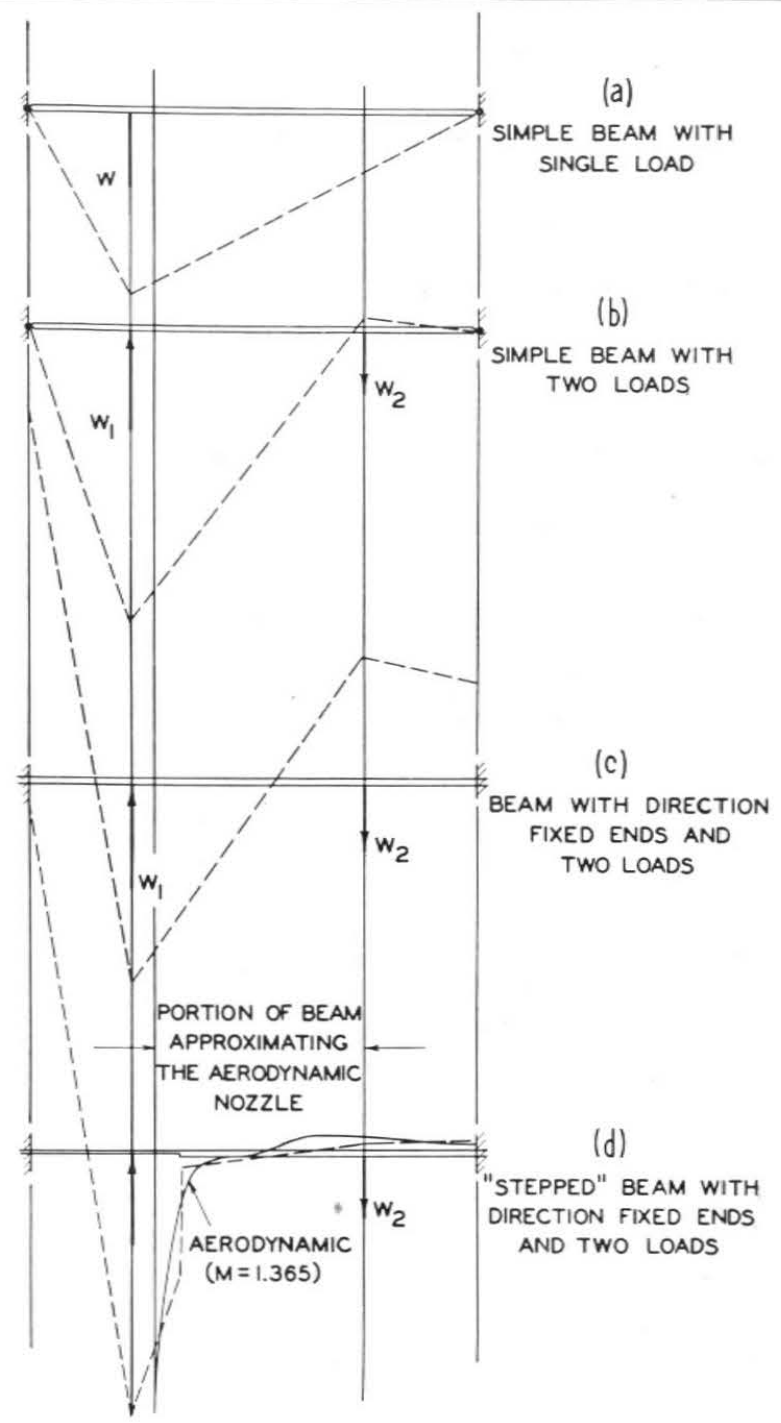

FIG. 4. Curvatures of elastic and aerodynamic shapes.

and having direction-fixed ends. The location of the jacks and the step in the plate was determined by trial to give the best overall reproduction of the aerodynamic shapes over the required range.
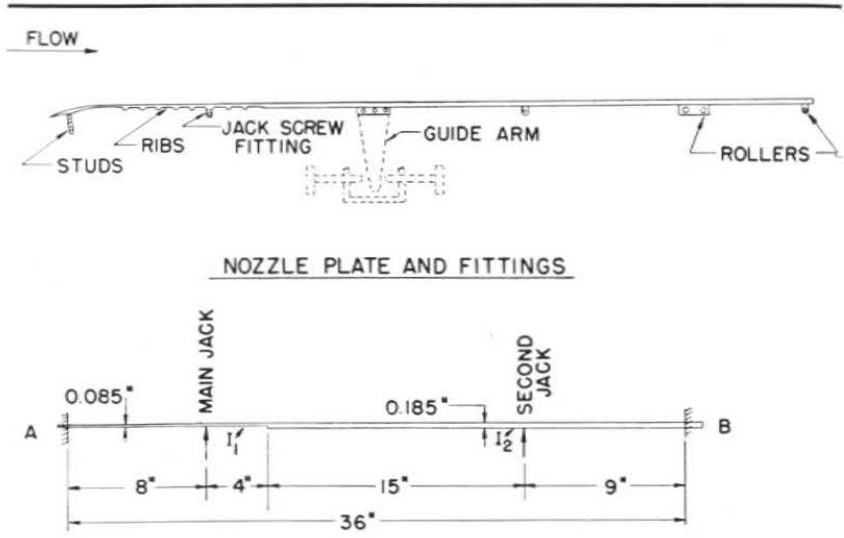

REPRESENTATION AS FIXED-END BEAM

FIG. 5. 


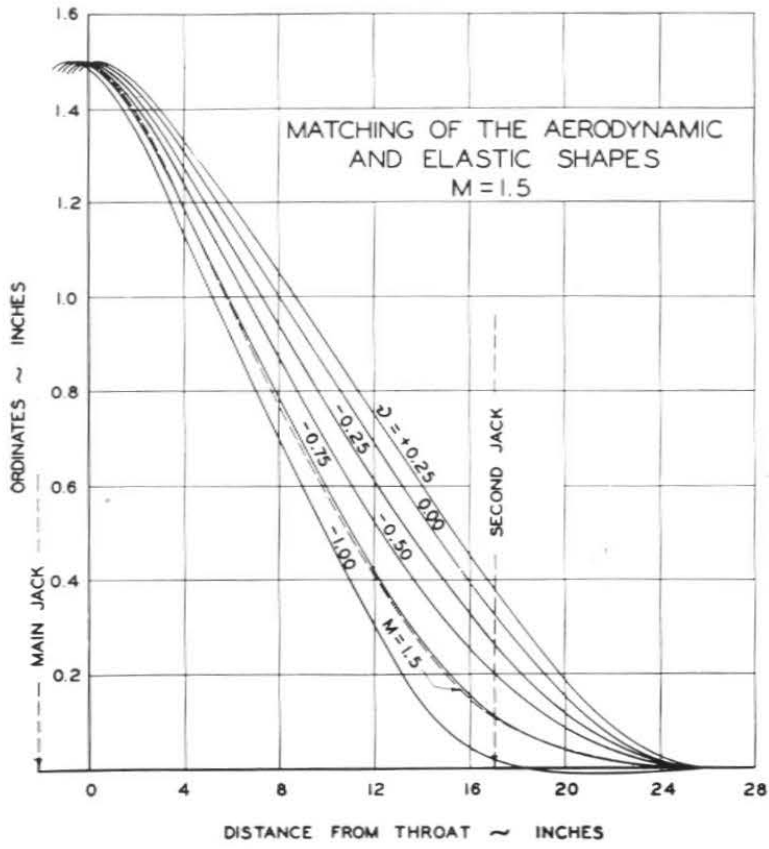

FIG. 6.

FLEXIBLE NOZZLE CONTROL SETTINGS

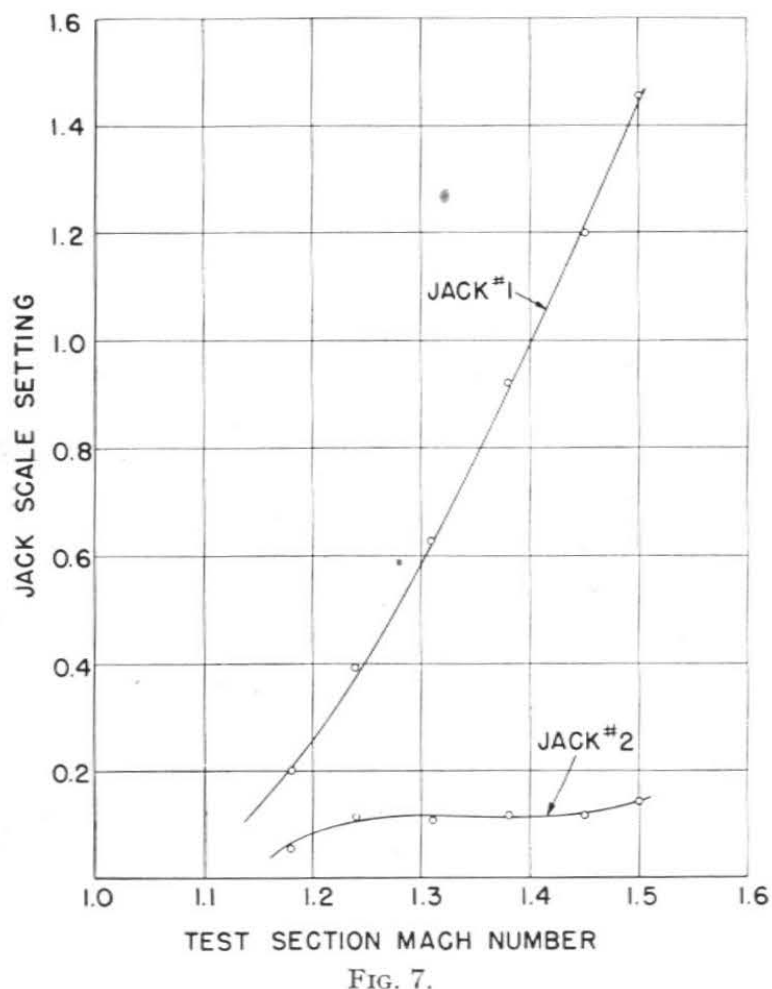

\section{(3) Determination of Control Settings}

The restriction on the deflection curve of the plate when it is required to reproduce an aerodynamic shape is that it must have a prescribed maximum deflection. This is given by the unique height ratio $h / h^{*}$ associated with a desired supercritical flow in the test section. Here, $h$ is the height of the two-dimensional test section, and $h^{*}$ is the height at the throat. Knowing the dimensions, end conditions, and type of loading on the plate, the elastic influence curves of the configuration can be calculated. These permit a determination of all the possible plate shapes (Fig. 6) with a given maximum deflection in terms of the load ratio $\nu=$ $W_{2} / W_{1}$, where $W_{1}=$ load in pounds on the main jackscrew and $W_{2}=$ load on the second jackscrew. A superposition of the required aerodynamic shape and the corresponding plate curves serves then to determine the optimum value of $\nu$, and the control settings are computed from the deflection influence functions of the plate. A representative case of matching of the aerodynamic and elastic curves for $M=1.5$ is shown in Fig. 6 , the vertical scale being exaggerated to increase the accuracy of matching. Fig. 7 shows the final curves from which control settings for any Mach Number within the design range may be obtained. It will be observed that over almost the entire range of operation only the main jack setting is required to be altered.

\section{Fabrication of the Nozzle Plate}

The problem in fabrication was to obtain a relatively thin, high-strength plate free from local deformation, particularly local deformations near the attachment fittings.

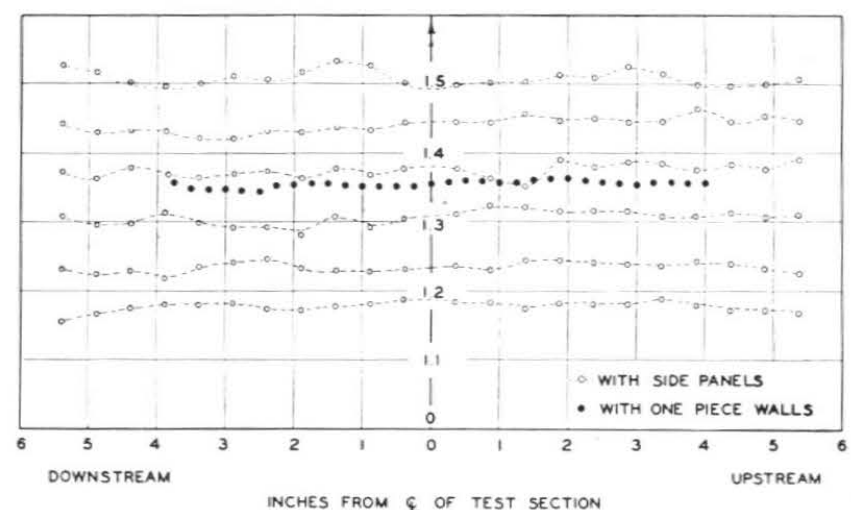

FIG. 8a. Horizontal Mach Number distribution in tunnel.

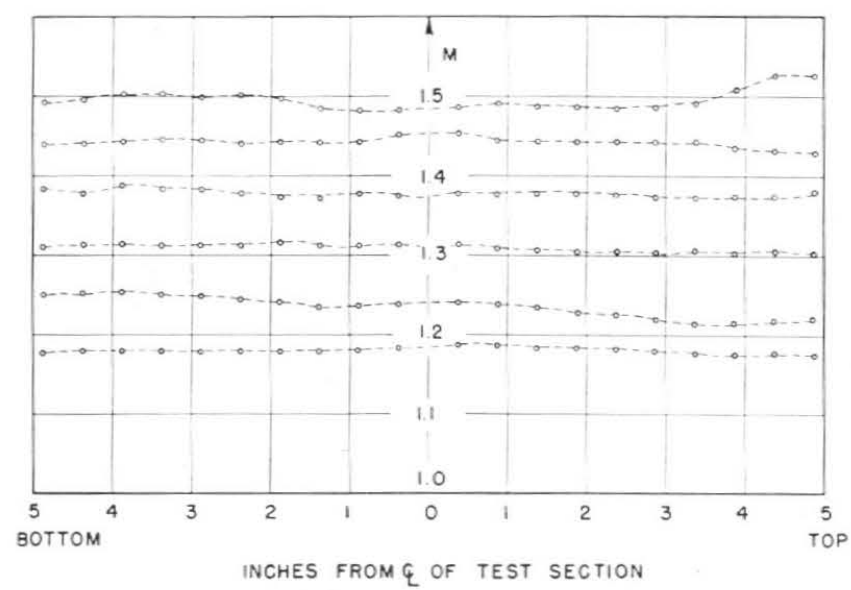

FIG. 8b. Vertical Mach Number distribution in tunnel 


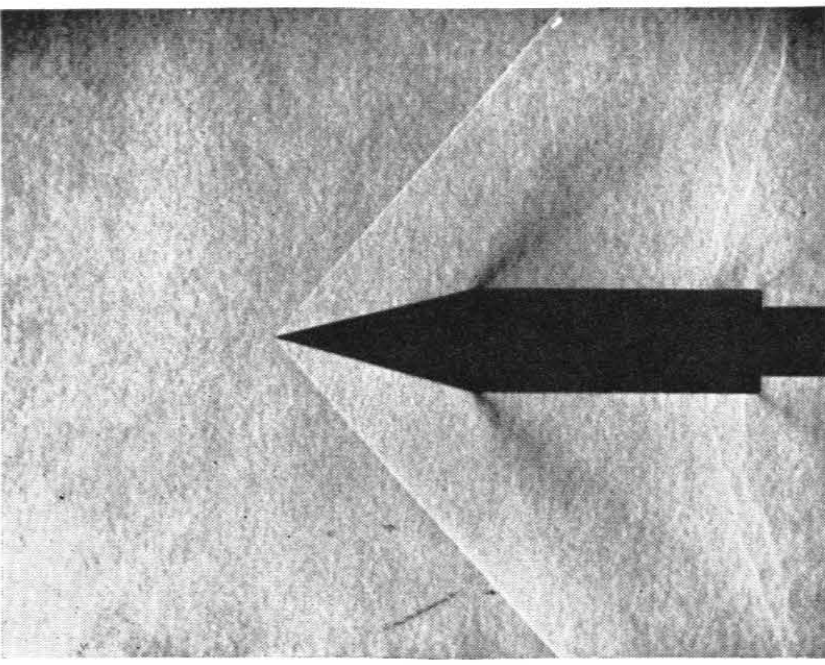

FIG. 9. Schlieren of flow past a cone. Cone half angle $=15^{\circ}$. $M=1.38$.

\section{(1) Choice of Material}

From simple beam theory for a beam with fixed ends and given deflection curve and thickness distribution,

stress $\sigma \sim E t$

deflection load $W \sim E t^{3}$

where

$E=$ modulus of elasticity of the beam material

$t=$ some reference thickness of beam

For the plate to be stable during operation, $W$ and $t$ must be kept as high as possible. A typical comparison between iron and copper alloys shows that, for a given factor of safety,

and

$$
t_{\text {steel }} / t_{\text {bronze }} \doteq 1.5
$$

$$
W_{\text {steel }} / W_{\text {bronze }} \doteq 7
$$

These considerations and problems of welding and heat-treatment dictated the choice of steel. SAE 6150 , an alloy spring steel, was found to meet the requirements.

\section{(2) Machining of Plate}

The plate with "step" and stiffening ribs was machined from a $3 / 8^{-}$by 5 -in. piece of annealed SAE 6150 , the studs and fittings also being machined from the same material. About 0.05 in. of extra material was left on the upper surface of the plate for final surface grinding.

\section{(3) Attachment of Fittings}

This was done by copper brazing in a hydrogen atmosphere furnace at $2,000^{\circ} \mathrm{F}$. (above the heat-treat- ment temperature). During this operation the plate was clamped in a steel jig.

\section{(4) Heat-Treatment}

The plate was heat-treated to give a Rockwell hardness of C-38, corresponding to a yield of $154,000 \mathrm{lbs}$. per sq.in. During the normalizing, quenching, and tempering processes, the plate was clamped in a jig. The results obtained were extremely satisfactory. There are no local distortions in the plate.

\section{(5) Surface Grinding}

The working surface of the plate was ground to a polish finish, eliminating all surface irregularities.

\section{(6) Stress Test}

Since the nozzle plate was to carry extremely high stresses in its fully deflected state, a strain-gage test was made to ensure safe operation. The maximum stress produced in the plate when set for $M=1.5$ was found to be $110,000 \mathrm{lbs}$. per sq.in. This gives a factor of safety of 1.4 .

\section{Evaluation and Calibration}

Figs. $8 \mathrm{a}$ and $8 \mathrm{~b}$ show the results of pressure surveys of the test section made at the various design Mach Numbers. The vertical distributions, Fig. $8 \mathrm{~b}$, reveal the effect of waves originating at the nozzle and indicate uniform flow with negligible gradients over the entire operating range. Fig. 9 is a schlieren photo-

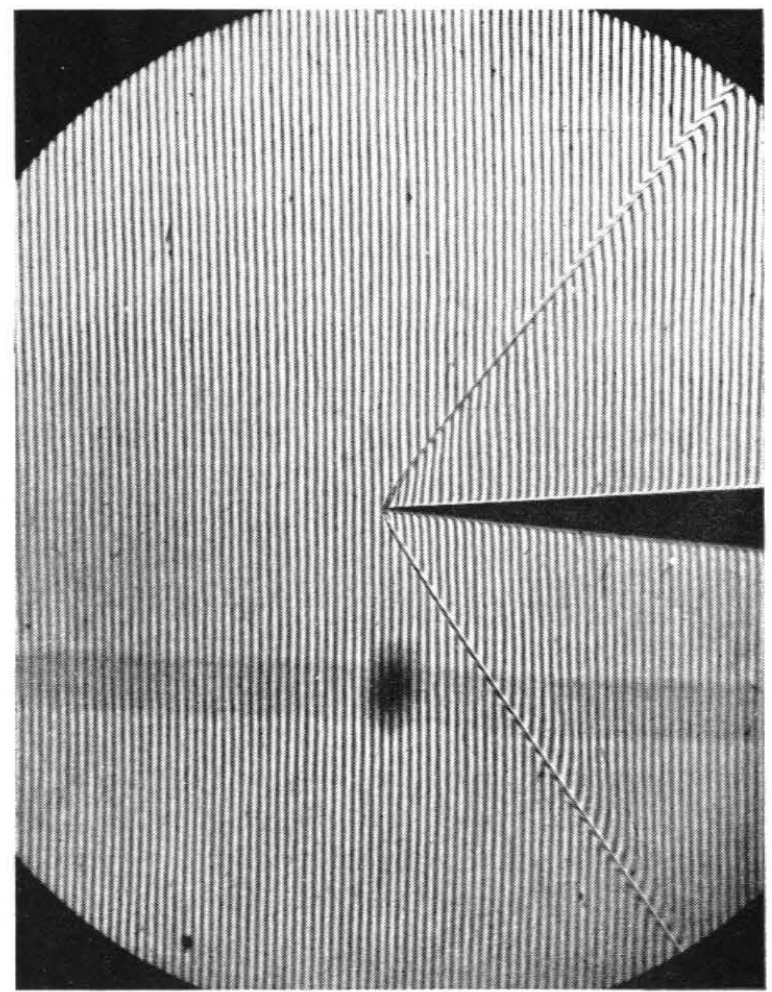

FIG. 10. Interferogram of flow past a wedge. Wedge half-angle $=4.5^{\circ} . M=1.37$. 


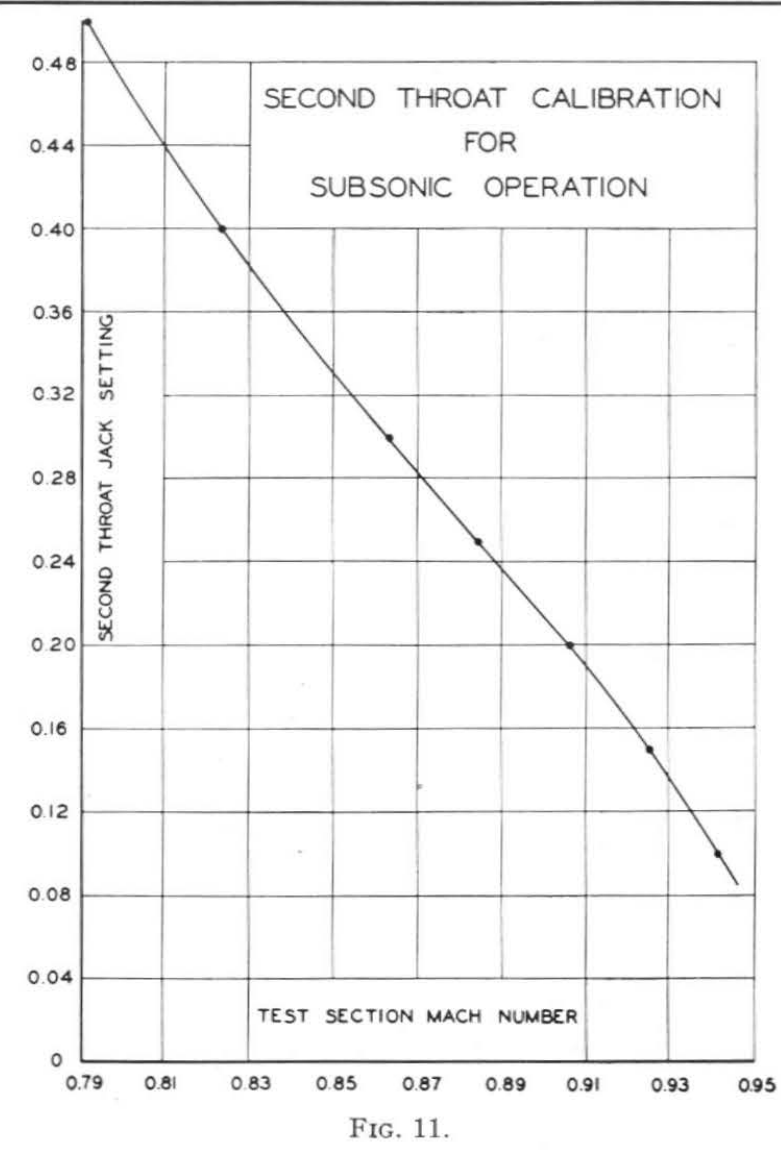

graph, and Fig. 10 is an interferogram of the flow in the test section. The straight head wave in Fig. 9 and the straight interference fringes in Fig. 10 confirm the uniform wave free flow indicated by the pressure surveys. The somewhat greater variations in the horizontal surveys (Fig. 8a) are due to the small disturbances introduced at the joints in the sectioned sidewalls. The use of continuous panels for the sidewalls reduces the variations in the horizontal direction to the same order as in the vertical surveys (see Fig. 8a). Figs. 7 and 11 , respectively, show the calibration curves for the controls over the supersonic and subsonic range of operation of the tunnel. The change from supersonic to subsonic flow or vice versa can be accomplished without shutting down the tunnel.

\section{CONClusion}

A flexible relatively high-strength plate free from local distortions has been successfully designed and used for the production of uniform shock-free flow over the range $M=1.1$ to 1.5 . The plate is vibrationally stable during operation, and the repeatability of flows is excellent.

\section{REFERENCE}

${ }^{1}$ Puckett, A. E., Supersonic Nozzle Design, J. Appl. Mech., December, 1946.

\section{Notice to Contributors}

Manuscripts submitted for publication must be double- or triple-spaced originals. There should be wide margins on both sides of the sheets and triple spacing around formulas to allow for the marking of directions for the printer.

Original drawings (jet black India ink on white paper or tracing cloth) should accompany the manuscript. (Blueprints are not acceptable.) Photographs must be on glossy white paper. The smallest lettering on 8 - by 10-in. figures should be no less than $1 / 4$ in. high.

Only the simplest formulas should be typewritten; all others should be carefully written in pen and ink. The difference between capital and lower-case letters and Greek symbols should be clearly distinguished.

See Inside Back Cover of this issue for further details. 